\title{
ASSISTÊNCIA HUMANIZADA: PERCEPÇÃO DO ENFERMEIRO INTENSIVISTA
}

\section{HUMANIZED CARE: PERCEPTION OF INTENSIVE CARE NURSES}

\section{ATENCIÓN HUMANIZADA: PERCEPCIÓN DEL ENFERMERO INTENSIVISTA}

\author{
Emilenny Lessa dos Santos ${ }^{1}$ \\ Savia Nobre de Araújo Dórea ${ }^{2}$ \\ Maria da Piedade Gomes de Souza Maciel ${ }^{3}$ \\ Leila Karoline Ferreira dos Santos ${ }^{1}$ \\ Mariana Barbosa da Silva ${ }^{1}$ \\ Maria Goretti Lins Moraes
}

Como citar este artigo: Santos EL, Dórea SNA, Maciel MPGS, Santos LKF, Silva MB, Moraes MGL. Assistência humanizada: percepção do enfermeiro intensivista. Rev baiana enferm. 2018;32:e23680.

Objetivo: analisar a percepção do enfermeiro intensiva sobre a assistência humanizada. Método: estudo qualitativo de cunho analítico realizado em um hospital público do estado de Alagoas, Brasil, nos meses de setembro e outubro de 2016. O instrumento de coleta de dados foi a entrevista semiestruturada aplicada junto a dez enfermeiros. Os dados foram trabalhados mediante análise de conteúdo na modalidade temática. Resultados: as três categorias que emergiram das falas tratam de aspectos da humanização como ferramenta de trabalho, associada ao uso da tecnologia e sua influência na recuperação do paciente crítico. Conclusão: na percepção dos enfermeiros intensivistas, ofertar uma assistência agregada à humanização é importante, por influenciar no tratamento e na recuperação do paciente.

Descritores: Humanização da assistência. Unidade de Terapia Intensiva. Cuidados de enfermagem.

Objective: analyze the perception of intensive care nurses have about humanized care. Method: this is a qualitative analytical study conducted in a public hospital in the state of Alagoas, Brazil, in September and October 2016. Data were collected through a semi-structured interview applied to ten nurses, and submitted to a thematic content analysis. Results: three categories were defined from the answers provided by the interviewees addressing aspects of bumanization as a work tool in intensive care units, associated with the use of technology and its influence on the recovery of critically ill patients. Conclusion: in the perception of intensive care nurses, offering humanized care is important, since it influences the treatment and recovery of patients.

Descriptors: Care bumanization. Intensive care unit. Nursing care.

Objetivo: analizar la percepción del enfermero intensivista acerca de la atención bumanizada. Método: estudio cualitativo de cuño analítico, realizado en un hospital público del estado de Alagoas, Brasil, en los meses de setiembre y octubre de 2016. El instrumento de recolección de datos fue la entrevista semiestructurada aplicada a diez

\footnotetext{
Enfermeiras. Maceió, Alagoas, Brasil. lessa.emilenny@outlook.com

Enfermeira. Especialista em Enfermagem em Centro Cirúrgico. Maceió, Alagoas, Brasil.

Enfermeira. Mestre em Ensino na Saúde. Maceió, Alagoas, Brasil.
} 
enfermeros. Los datos fueron trabajados a través de análisis de contenido, en su modalidad temática. Resultados: las tres categorías que surgieron de las conversaciones tratan sobre aspectos de la humanización como herramienta de trabajo, asociada al uso de la tecnología y su influencia en la recuperación del paciente crítico. Conclusión: en la percepción de los enfermeros intensivistas, ofrecer una atención con agregación de la humanización es importante, por el hecho de influir en el tratamiento y en la recuperación del paciente.

Descriptores: Humanización de la atención. Unidades de cuidados intensivos. Atención de enfermería.

\section{Introdução}

Humanização é um termo que é associado a vários significados. No sentido literal da palavra, significa efeito de humanizar, isto é, tornar humano, tornar benévolo, mostrar-se benévolo. A humanização também pode ser considerada como algo inato do ser humano; aquilo que nasce com ele e o ajuda a guiar suas relações em sociedade baseadas na caridade, compaixão e bondade ${ }^{(1)}$.

Com o passar dos anos, a questão da humanização ganhou destaque não só na área da saúde; outras áreas da vida social também têm sido beneficiadas. Na saúde, de forma geral, o termo relaciona-se às questões éticas ligadas ao ato de cuidar de pacientes, para melhoria nas relações entre os envolvidos nesse processo e nas condições do trabalho em saúde ${ }^{(2)}$.

Em relação ao contexto da humanização no Brasil, sabe-se que é um país em desenvolvimento, e isso faz com que, no seu cotidiano, existam problemas que dificultam a efetivação das diretrizes do Sistema Único de Saúde (SUS). Com isso, surge a necessidade de criar estratégias para reorganizar o modelo de assistência à saúde vigente, priorizando a oferta de assistência baseada nos valores humanos e na qualidade do cuidado. Diante disso, as iniciativas de humanização dos serviços de saúde no Brasil surgem como uma alternativa de transformação ${ }^{(3)}$.

Todavia, o aspecto humano do cuidado é um dos mais difíceis de ser implementado, principalmente quando se trata de unidades de terapia intensiva (UTI), onde a rotina diária e a complexidade do ambiente tanto físico quanto funcional faz com que os profissionais vejam-se cercados por paradoxos, como o duelo entre vida e morte, sucesso e fracasso, processo de tomada de decisões e questões éticas, dificultando, assim, a prestação da assistência humanizada ${ }^{(4)}$.

A UTI é um setor diferenciado do hospital, pois conta com uma organização específica e uma tecnologia moderna voltadas para atender melhor o paciente crítico. Devido ao estado clínico desse tipo de paciente, o tratamento muitas vezes acaba tornando-se invasivo e agressivo, pela necessidade de intervenções a serem feitas. Isso caracteriza esse setor como um ambiente de alta complexidade. Além disso, a UTI acaba causando a despersonalização do ser humano, o qual se encontra longe da família e de amigos, num lugar desconhecido, nem um pouco aconchegante, cercado de profissionais e da incerteza do que irá acontecer ${ }^{(2)}$.

Nesse sentido, abordar a humanização em UTI é relevante, por possibilitar entender e esclarecer que existem particularidades intrínsecas à assistência de enfermagem nesse setor hospitalar. Além disso, ajuda na compreensão de que a assistência humanizada envolve um conjunto de conhecimentos, práticas e tomadas de decisão que visam à promoção e recuperação dos pacientes internados ${ }^{(5)}$.

$\mathrm{O}$ estudo procurou responder a seguinte questão norteadora: Como o enfermeiro intensivista percebe a assistência humanizada? E teve como objetivo analisar a percepção do enfermeiro intensivista sobre a assistência humanizada.

\section{Método}

Trata-se de uma pesquisa qualitativa realizada em um hospital público do estado de Alagoas, 
Brasil, referência para o atendimento de alta complexidade. No período de coleta de dados, trabalhavam na UTI geral 12 enfermeiros.

Os seguintes critérios de inclusão foram estabelecidos: enfermeiros de ambos os sexos, sem restrição de idade, com tempo superior a 2 anos de trabalho no setor, por possuírem vivência suficiente com situações que implicassem em embasamento para discutir sobre humanização. Foram critérios de exclusão: enfermeiros que trabalhavam em outros setores do hospital, que se encontravam de férias e/ou licença médica. O total de participantes da pesquisa foi dez, porque dois não atendiam aos critérios estabelecidos.

Os enfermeiros que participaram do estudo foram convidados a assinar o Termo de Consentimento Livre e Esclarecido (TCLE), consolidando a participação voluntária. Para assegurar o anonimato e o sigilo das informações na identificação dos participantes, utilizou-se a expressão "(E)", significando Enfermeiro, seguida da numeração de 1 a 10, de acordo com a ordem de realização das entrevistas.

A coleta de dados ocorreu nos meses de setembro e outubro de 2016. Foi aplicada uma entrevista semiestruturada cujo roteiro contava com perguntas abertas. O gravador foi utilizado para gravar os depoimentos coletados. Posteriormente, as falas foram transcritas na íntegra. Para analisar os discursos dos entrevistados, optou-se por utilizar a técnica de análise de conteúdo temática, a qual apresenta as seguintes etapas: pré-análise (leitura flutuante); exploração do material (os dados são codificados em unidades de registro); tratamento dos resultados e interpretação (categoriza-se e, posteriormente, reagrupa-se em função de características comuns) ${ }^{(6)}$.

A pesquisa seguiu os pressupostos éticos da Resolução n. 466/12 do Conselho Nacional de Saúde ${ }^{(7)}$. Foi aprovada pelo Comitê de Ética em Pesquisa (CEP) da Universidade Estadual de Ciências da Saúde de Alagoas, sob o Parecer n. 1.673.632 e CAEE 53338716.7.0000.5011.

\section{Resultados e Discussão}

Os participantes do estudo caracterizaram-se por serem 9 do sexo feminino e 1 do sexo masculino, faixa etária entre 40 e 49 anos, média de experiência de 15 anos na área de enfermagem e de 10 anos na área de UTI.

Emergiram as seguintes categorias, que tiveram como referencial teórico a Política Nacional de Humanização: Humanização como ferramenta de trabalho na UTI; Interferência da tecnologia no emprego da humanização; Impacto da assistência humanizada na recuperação do paciente crítico.

\section{Humanização como ferramenta de trabalbo na UTI}

A humanização tornou-se amplo tema de discussão com a criação da Política Nacional de Humanização (PNH). É proposta como política transversal, como um conjunto de princípios e diretrizes traduzidos nas práticas de saúde, serviços e nas instâncias do sistema, caracterizando uma construção coletiva. A política veio para propiciar o debate acerca da humanização no SUS, para ajudar na consolidação de seus princípios e diretrizes e pode ser usada como ferramenta de trabalho ${ }^{(8)}$.

Entende-se que cuidar de forma humanizada é uma necessidade atual, visto que, muitas vezes, o cuidado acaba sendo a aplicação de uma técnica de enfermagem. Entretanto, para que se possa humanizar, é importante compreender que o ser ao qual está sendo aplicada a técnica é um agente biopsicossocial que precisa ser atendido de forma integral e não só no que se refere ao seu quadro patológico ${ }^{(5)}$.

$\mathrm{Na}$ UTI onde foi realizado o presente estudo, quando questionados sobre as ações humanizadoras desenvolvidas, os profissionais assim as descreveram:

\footnotetext{
Eu faço uma assistência bumanizada, tendo um olbar mais cuidadoso. E, quando a gente começa a ver que pode melhorar nos procedimentos, no cuidado, a gente começa a ter um progresso maior na assistência. Porque não é só falar, conversar. Acho que o cuidado em si com o paciente melhora no atendimento e na questão da humanização. (E2).
}

Presto uma assistência bumanizada, uma vez que levo em consideração as necessidades do paciente. Acho importante enxergá-lo como um ser humano e tento agir em prol do seu bem-estar e recuperação. (E3). 
A partir do momento que você vai além da assistência prestada, consegue ouvir, olhar, tocar o paciente, vê-lo como um ser bumano completo, que tem suas crenças, princípios, família. Isso é o ponto inicial para uma assistência bumanizada, e isso faz toda diferença. (E8).

Tais discursos revelam que os enfermeiros reconhecem a importância de se ter uma visão holística para prestar uma assistência voltada a atender o paciente de forma integral. Entendem que humanizar é mais do que conversar, ter fala mansa, ter atitudes bondosas, caridosas; é algo bem mais amplo, pois é um processo complexo, abrangente e dinâmico, que envolve os diferentes agentes inseridos no contexto, como profissionais, pacientes e familiares. Humanização é principalmente uma mudança de comportamento e de atitudes dos profissionais diante dos pacientes e seus familiares. Os profissionais que atendem direta ou indiretamente os pacientes são os verdadeiros responsáveis pela humanização, uma vez que a conscientização da equipe de saúde a respeito do assunto permite que ela seja colocada em prática da melhor maneira possível e atingindo os objetivos propostos ${ }^{(9)}$.

A humanização não é uma técnica, um artifício; é processo que envolve todo o ambiente e os sujeitos que nele estão inseridos. E os profissionais que nesse ambiente trabalham, por sua vez, dão ao paciente um atendimento digno, pautado no respeito aos valores humanos, dentro das circunstâncias em que se encontra cada um no momento da internação na UTI.

Para que a humanização seja efetivada na prática de enfermagem, é preciso que haja uma interação entre profissional e cliente, um auxílio de todos os envolvidos no processo, como os gestores, trabalhadores e usuários do serviço. A humanização só acontece se houver um trabalho em conjunto; torna-se uma prática positiva e de qualidade, quando quem a pratica agrega valores e significado àquilo que está sendo feito ${ }^{(10)}$.

Nesse sentido, quando se discute sobre humanização na UTI, surge um desafio, pois se trata de um ambiente voltado ao atendimento de pacientes graves. Atualmente a realidade da humanização nas UTIs ainda tem muito o que ser repensado, melhorado. Principalmente nos hospitais públicos, onde faltam condições para que os profissionais trabalhem com uma boa ergonomia, remuneração e estrutura física adequadas para exercerem seu trabalho de forma digna e satisfatória. A falta de boas condições de trabalho interfere negativamente na prestação da qualidade de uma boa assistência humanizada.

\section{Interferência da tecnologia no emprego da bumanização}

Vivemos em um mundo marcado por inovações tecnológicas e a UTI é um espaço onde surgem frequentemente novos equipamentos e dispositivos que ajudam e melhoram a qualidade do atendimento ao paciente. Essas inovações exigem dos profissionais maior qualificação para saber usar a tecnologia disponível de modo eficiente e seguro, sem esquecer os princípios éticos que norteiam a sua profissão ${ }^{(11)}$. A UTI é um ambiente de alta complexidade e a tecnologia é um fator marcante desse setor, o que levanta várias indagações a respeito de até que ponto isso traz benefícios ou riscos para a prestação do cuidado humanizado. Sobre esse contexto, os enfermeiros participantes da pesquisa relataram:

\footnotetext{
Em alguns momentos, você percebe que alguns profissionais valorizam muito mais o equipamento do que a clínica. Antes a clínica era soberana; você precisava de pouca coisa pra chegar a um diagnóstico. Hoje, infelizmente, alguns profissionais não valorizam os achados clínicos, não dão importância a anamnese e só se preocupam em solicitar exames de última geração. (E1).

Às vezes, alguns profissionais só querem fazer um procedimento, um diagnóstico, se tiver todos os exames, uma tomografia, uma ressonância, entre outras coisas. E antes, o exame físico era crucial para avaliar o paciente juntamente com a anamnese. (E3).

O avanço tecnológico é um aliado muito grande na recuperação do paciente. Por outro lado, tem muito maquinário, e como ele dá tudo pronto, fica muito mais fácil, $e$ isso é um fato que traz um certo prejuízo em relação ao toque, a você observar outros sinais que não estejam atrelados ao maquinário. (E4).
}

Diante disso, sendo a UTI um ambiente de alta complexidade e cercado de inovações tecnológicas, em relação à interferência do uso dessa tecnologia na assistência humanizada, os participantes do estudo afirmaram que existem 
profissionais que, em alguns momentos, supervalorizam os equipamentos e os dispositivos tecnológicos em detrimento da relação enfermeiro/ paciente. Com isso, acabam exercendo uma assistência fragmentada e baseada no modelo curativista, que visa obter somente a cura da patologia; o paciente é visto apenas como um objeto de estudo. A realização da assistência humanizada torna-se, assim, um desafio, pois não é lembrado que o cuidado está sendo ofertado a uma pessoa, e a tecnologia passa ser o foco principal da atenção.

O avanço tecnológico ajuda no atendimento imediato do paciente, dá segurança para a equipe que está atendendo, e isso contribui para melhorar a recuperação do paciente. Entretanto, também colabora para tornar as relações humanas mais distantes, pois torna-se um método de dependência entre profissionais e eles acabam preocupando-se mais com as informações advindas dos aparelhos. Isso contribui para o distanciamento entre profissional e paciente, fazendo com que os dados subjetivos do cuidado e a integralidade da assistência fiquem comprometidos.

No cenário de UTI, é imprescindível que o enfermeiro tenha sempre conhecimentos técnico e científico para poder realizar procedimentos e intervenções inerentes a esse setor hospitalar. Entretanto, é importante que não ocorra a supervalorização do aparato tecnológico, para que o cuidar, o saber ouvir, o saber se colocar no lugar do outro não sejam esquecidos. É crucial, para uma boa assistência, aliar o uso da tecnologia ao cuidado ofertado(5).

Os enfermeiros também reconheceram que a tecnologia era importante no ambiente de UTI, desde que a valorização principal fosse o paciente, uma vez que o paciente crítico necessita de uma monitorização contínua e cuidados complexos que auxiliem na melhora ou estabilização do seu quadro clínico. Contudo, revelaram ainda a importância do uso adequado da tecnologia, ressaltando que ela deve ser aliada na assistência humanizada e não tida como objeto principal na realização do cuidado, como pode ser percebido nas falas a seguir:

Vai depender da visão de cada profissional. Porque, na forma ideal, você tem que usar a tecnologia como acessório e não como foco principal. A percepção do profissional é muito mais difícil de falhar do que o equipamento, do que a tecnologia. Só que, pra isso, é preciso ter o preparo de saber olhar o paciente, a clínica e não só a tecnologia. (E4).

Uma UTI bem equipada, com tecnologia disponivel, com monitorização invasiva e não invasiva, com os procedimentos necessários sendo feitos de forma efetiva, rápida, os pacientes se recuperam muito mais rápido. (E7).

Tomando como foco a UTI, pode-se considerar que, nesse ambiente, o impacto da tecnologia é facilmente observado, pois esses setores prestam assistência aos pacientes criticamente enfermos. Nesses ambientes, a prática acaba sendo mecanizada e especializada, o que leva à necessidade de refletir-se sobre o sentido real da assistência como uma forma de cuidado, a qual deve ser associada à humanização. Os profissionais de saúde precisam fortalecer a comunicação, o contato e valorizar os usuários, pois, ao dialogar e saber ouvir suas queixas, eles têm como possibilitar a resolubilidade e o cuidado integral $^{(10)}$.

\section{Impacto da assistência humanizada na recuperação do paciente crítico}

A PNH ressalta que a humanização não deve ser vista como programa, mas como política que atravessa as diferentes ações e instâncias gestoras do SUS, para que se possa efetivar a construção de trocas solidárias e comprometidas com a dupla tarefa de produção de saúde e produção de sujeitos, uma vez que a humanização busca a valorização dos diferentes sujeitos envolvidos no processo de produção da saúde ${ }^{(8)}$.

O contexto hospitalar, no que tange às ações do profissional nesse espaço e no cuidado em si, traz consigo uma visão fragmentada do homem, em que o funcionamento do seu corpo é associado a uma máquina. Nesse ambiente, a assistência apresenta-se de forma individualizada e executada de forma mecânica; o profissional 
de saúde é cobrado, para que a execução dos afazeres técnicos ocorra em elevada quantidade e em pouco tempo. Por isso, a humanização vem como uma alternativa para mudar essa realidade, já que se propõe a compreender as sensações e impressões subjetivas dos profissionais intensivistas, pois sabe-se que, por mais que a excelência técnica seja necessária, sozinha ela não é suficiente para que o paciente crítico tenha uma recuperação no seu aspecto biopsicossocial $^{(5)}$.

Em relação à influência da assistência humanizada na recuperação dos pacientes críticos, os enfermeiros reconhecem que contribui positivamente, ao oferecer uma assistência voltada para as reais necessidades do indivíduo, ouvindo com atenção, solucionando problemas, proporcionando conforto durante todo o processo de internação na UTI, como pode ser observado nos discursos a seguir:

Na assistência humanizada, o paciente é acolbido melhor; são levadas em consideração suas necessidades. Desta forma, ele tem uma melhor resposta na sua recuperação. (E3).

Uma pessoa que é internada em uma UTI, que tá longe da familia, restrita no leito, dependente das pessoas pra tudo, numa rotina totalmente diferente do seu cotidiano de vida, consequentemente estará estressada. Então, se você não prestar uma boa assistência humanizada, vai dificultar a recuperação dela. (E7).

O cuidado de enfermagem com o emprego da humanização em cada técnica a ser executada, desde a manipulação de um monitor até a higiene corporal, possibilita o exercício do escutar, valorizando as queixas e as necessidades individuais, além da atenção aos aspectos psicológicos, emocionais e afetivos do paciente. Como foi relatado por E7, o processo de internação interfere diretamente na vida do paciente, trazendo sentimentos de angústia, dúvidas e medo, tornando-o, muitas vezes, coadjuvante desse processo.

O cuidado humanizado eleva as chances de sobrevivência e recuperação dos pacientes críticos, mas, como a UTI é um ambiente onde o inesperado é sempre presente na rotina diária, já que acontecem muitas intercorrências, é necessário que os profissionais sensibilizem-se e compreendam a importância da assistência humanizada, para que ela possa ser inserida na sua conduta de trabalho ${ }^{(12)}$.

A produção do conhecimento acerca da assistência humanizada no ambiente de UTI possibilita que os enfermeiros reflitam sobre uma temática que, muitas vezes, acaba não sendo tão explorada no cotidiano de trabalho, em virtude da rotina diária do setor e das atribuições inerentes a esses profissionais. Essa reflexão pode fazer com que os enfermeiros repensem suas condutas perante a assistência que proporcionam aos pacientes em estado crítico, para que sejam de qualidade e baseadas nos valores humanísticos.

Apresenta-se como limitação da pesquisa o fato ter sido realizada em apenas um hospital. Desta forma, destaca-se a necessidade de estudos de continuidade em outros hospitais e cenários, para se conhecer diferentes realidades, a fim de ampliar as percepções dos sujeitos acerca da temática, buscando enriquecer os resultados obtidos.

\section{Conclusão}

Com a realização do presente estudo foi possível compreender que os enfermeiros reconhecem a importância de se ter uma visão holística para a prestação de uma assistência voltada ao atendimento ao paciente de forma integral.

Os participantes perceberam que a oferta de um atendimento de qualidade, pautado no respeito aos valores humanos, que caracteriza o emprego da humanização no ambiente da UTI, possibilita resultados positivos no tratamento e na recuperação do paciente crítico no seu aspecto biopsicossocial. Compreenderam que a humanização não é uma técnica, um artifício, mas se trata de um processo complexo, abrangente e dinâmico, que envolve todo o ambiente e os sujeitos que nele estão inseridos.

Por fim, é válido salientar que os profissionais devem refletir acerca das suas condutas e ações realizadas durante o processo do cuidado, 
passando a ter atitudes humanísticas pautadas no atendimento humanizado, baseado nas diretrizes de acolhimento, ambiência e defesa dos direitos humanos preconizadas pela $\mathrm{PNH}$.

\section{Colaborações:}

1. concepção, projeto, análise e interpretação dos dados: Savia Nobre de Araújo Dórea e Maria da Piedade Gomes de Souza Maciel;

2. redação do artigo e revisão crítica relevante do conteúdo intelectual: Emilenny Lessa dos Santos, Leila Karoline Ferreira dos Santos, Mariana Barbosa da Silva e Maria Goretti Lins Moraes;

3. aprovação final da versão a ser publicada: Emilenny Lessa dos Santos, Savia Nobre de Araújo Dórea e Maria da Piedade Gomes de Souza Maciel.

\section{Referências}

1. Chernicharo IM, Silva FD, Ferreira MA. Caracterização do termo humanização na assistência por profissionais de enfermagem. Esc Anna Nery [online]. 2014 jan-mar [cited 2016 Oct 5];18(1):156-62. Available from: http://dx.doi. org/10.5935/1414-8145.20140023

2. Pereira MMM. À beira do leito: sentimentos de pacientes durante a passagem de plantão em Unidade de Terapia Intensiva [dissertação]. Natal (RN): Universidade Federal do Rio Grande do Norte; 2011. [cited 2016 Oct 18]. Available from: repositorio. ufrn.br:8080/jspui/handle/123456789/14733

3. Reis CCA, Sena ELS, Fernandes MH. Humanization care in intensive care units: integrative review. Rev pesqui: cuid fundam (online). $2016 \mathrm{abr} / \mathrm{jun}$ [cited 2016 Oct 13];8(2):4212-22. Available from: http://www.seer.unirio.br/index.php/cuidado fundamental/article/view/3983/pdf_1859

4. Pereira MMM, Germano RM, Câmara AG. Aspectos da assistência de enfermagem em unidade de terapia intensiva. Rev Enferm UFPE [online]. 2014 mar [cited 2016 Nov 12];8(3):545-54. Available from: file:///C:/Users/usuario/Downloads/344453349-1-PB.pdf

5. Oliveira LM, Bastos L. Humanização em UTI: um estudo bibliográfico sobre as peculiaridades necessárias e diversas situações no processo humanizar. Tocantins: Instituto Federal de Educação, Ciência e Tecnologia; 2013 [cited 2016 Oct 16]. Available from: http://campusaraguatins. ifto.edu.br/portal/saude/index.php/artigos/109humanizacao-em-uti-um-estudo-bibliograficosobre-as-peculiaridades-necessarias-e-diversassituacoes-no-processo-humanizar

6. Bardin L. Análise de conteúdo. São Paulo: Edições 70; 2011.

7. Brasil. Ministério da Saúde. Conselho Nacional de Saúde. Resoluçãon. 466, de 12 de dezembro de 2012. Aprova as diretrizes e normas regulamentadoras de pesquisas envolvendo seres humanos. Brasília; 2012. [cited 2016 Jan 28]. Available from: http:// bvsms.saude.gov.br/bvs/saudelegis/cns/2013/ res0466_12_12_2012.html

8. Brasil. Ministério da Saúde. Secretaria Executiva. Núcleo Técnico da Política Nacional de Humanização. HumanizaSus. Política Nacional de Humanização. A humanização como eixo norteador das práticas de atenção e gestão em todas as instâncias do SUS. Brasília; 2004 [cited 2016 Nov 13]. Available from: http://adcon.rn.gov. br/ACERVO/sesap/DOC/DOC000000000125646. PDF

9. Barbosa MDA. O trabalho do enfermeiro no ambiente das UTIs: a importância da humanização no desempenho efetivo das atividades [dissertação]. Vitória (ES): Instituto Brasileiro de Terapia Intensiva; 2013 [cited 2016 Nov 21]. Available from: www.ibrati.org/sei/docs/tese_619.doc

10. Rodrigues AC, Calegari T. Humanização da assistência na unidade de terapia intensiva pediátrica: perspectiva da equipe de enfermagem. REME rev min enferm. 2016 [cited 2016 Oct 18];20(933):19-25. Available from: http://www. reme.org.br/artigo/detalhes/1067

11. Vieira CA, Maia LFS. Assistência de enfermagem humanizada ao paciente em UTI. Rev Cient Enferm. 2013;9(3):17-22.

12. Farias FBB, Vidal LL, Farias RAR, Jesus ACP. Cuidado humanizado em UTI: desafios na visão dos profissionais de saúde. Rev pesqui cuid fundam (Online). 2013 out/dez [cited $2016 \mathrm{Nov}$ 21];5(4):635-42. Available from: https://dialnet. unirioja.es/descarga/articulo/4767896.pdf 
13. Pontifícia Universidade Católica de Minas Gerais. Orientações para elaboração de trabalho técnicos científicos: projeto de pesquisa, teses, dissertações, monografias entre outros trabalhos acadêmicos, conforme o Comitê Internacional de Editores de Revistas Médicas (VANCOUVER). Belo Horizonte; 2016 [cited 2017 Mar 4]. Available from: http://
portal.pucminas.br/imagedb/documento/DOC_ DSC_NOME_ARQUI20160217102140.pdf

Recebido: 20 de agosto de 2017

Aprovado: 6 de fevereiro de 2018

Publicado: 26 de abril de 2018

A Revista Baiana de Enfermagem utiliza a Licença Creative Commons - Atribuição-NãoComercial 4.0 Internacional. https://creativecommons.org/licenses/by-nc/4.0/ Este artigo é de acesso aberto distribuído sob os termos da Licença Creative Commons (CC BY-NC). Esta licença permite que outros remixem, adaptem e criem a partir do seu trabalho para fins não comerciais e, embora, os novos trabalhos tenham de lhe atribuir o devido crédito e não possam ser usados para fins comerciais, os usuários não têm de licenciar esses trabalhos derivados sob os mesmos termos. 